\title{
ANAESTHETIC CONCERNS IN FUNCTIONAL ENDOSCOPIC SINUS SURGERY
}

\author{
Vinaya R. Kulkarni', Sanyogita V. Naik²
}

${ }^{1}$ Associate Professor, Department of Anaesthesiology, BJG Medical College, Pune.

2 Professor and HOD, Department of Anaesthesiology, Government Medical College, Miraj, Maharashtra.

\section{ABSTRACT}

\section{BACKGROUND}

Functional endoscopic sinus surgery provides a challenge and an opportunity for the anaesthesiologists to provide surgeons with a surgical field, which can make this delicate surgery more safe, fast and precise. The article discusses causes of bleeding in functional sinus surgery.

\section{MATERIALS AND METHODS}

It focuses on various techniques and drugs, which can be used by anaesthesiologists to control bleeding. It also discusses the pros and cons of controlled hypotension during this surgery. Various techniques of local instillation of various drugs are discussed.

\section{RESULTS}

Various drugs and techniques are compared and advantages and disadvantages of each are discussed.

\section{CONCLUSION}

Premedication with various drugs, techniques of positioning and controlled hypotension are useful for control of bleeding in functional endoscopic sinus surgery.

\section{KEYWORDS}

Endoscopic Sinus Surgery, Controlled Hypotension.

HOW TO CITE THIS ARTICLE: Kulkarni VR, Naik SV. Anaesthetic concerns in functional endoscopic sinus surgery. J. Evolution Med. Dent. Sci. 2017;6(31):2567-2571, DOI: 10.14260/Jemds/2017/555

\section{BACKGROUND}

Chronic rhinosinusitis has a significant impact on health related and generic quality of life. It can cause high cost burden to both society and patients and may be associated highlights with absenteeism, loss of productivity and poor respiratory function. ${ }^{1}$

Most vital aspect of endoscopic sinus surgery is an optimal visibility in the surgical field. This invariably requires controlled hypotension and provision of good quality surgical field. This article reviews various modalities of provision of controlled hypotension and the method to assess the quality of surgical field.

It is a highly-sophisticated surgery, which has revolutionised the surgical management of chronic sinus diseases. It is a minimally invasive procedure done to restore the natural mucociliary clearance mechanism, drainage and aeration of the sinuses while maintaining the normal anatomy as much as possible. Bleeding is difficult to control due to extensive vascular supply in the sinus region. ${ }^{1}$

Major complications like optic nerve damage, damage to dura mater, CSF rhinorrhoea, meningitis and even death have been reported for FESS under general as well as local anaesthesia. ${ }^{1}$ This results from impaired visibility due to excessive bleeding during surgery. ${ }^{2}$

Financial or Other, Competing Interest: None.

Submission 21-02-2016, Peer Review 21-03-2017,

Acceptance 27-03-2017, Published 17-04-2017.

Corresponding Author:

Dr. Vinaya R. Kulkarni,

Flat A-202, Nakshatra Apartments,

Erandwane, Pune-411004.

E-mail: vinayabjmc@yahoo.com

DOI: $10.14260 /$ jemds $/ 2017 / 555$
The treatment of serious complications from the poor visibility due to excessive bleeding in the surgical field and the possibility of neurological damage makes it important for anaesthesiologists to produce optimal surgical conditions.

Bleeding occurs from intrabony vessels which are unsupported and capillaries which cannot be ligated. ${ }^{3}$ Antifibrinolysis and haemostasis are the two mechanisms, which can be used for optimal surgical field without endangering life or well-being of the patient. The need for blood transfusion is also reduced.

Many techniques have been proposed to improve the field of functional endoscopic sinus surgery. ${ }^{1}$ Many pharmacological as well as non-pharmacological techniques have been tried. ${ }^{1}$ SNP, NTG, ganglion blocking agents, volatile agents and $\mathrm{MgSO} 4$ have been tried for decreasing blood loss in nasal surgery. $4,5,6$

Here, we will try to review various measures followed for better surgical field. ${ }^{1}$ Bipolar diathermy, packing, local vasoconstrictor and induced hypotension are the most commonly used techniques. $4,5,6$

Diathermy can lead to local mucosal damage and delayed bleeding. ${ }^{4}$ Use of local vasoconstrictors can lead to endoscopic surgery is a minimally invasive technique that has found a definite place in all surgical techniques. It can range from endoscopic septoplasty, turbinoplasty and functional endoscopic sinus surgery to advanced surgery like endoscopic orbital and optic nerve decompression, endoscopic dacryocystorhinostomy and endoscopic skull base approaches. ${ }^{1}$

The advantages are absence of external scars, minimal damage to normal tissue and bone and short recovery time and length of hospital stay. But intraoperative bleeding presents a larger obstacle to endoscopic visualisation. ${ }^{1}$

The risk of complications increases with intraoperative bleeding. The most common indications are: chronic sinusitis 
refractory to medical treatment, recurrent sinusitis, nasal polyposis, antrochoanal polyps and sinus mucoceles.

Mucosa of nasal cavity, paranasal sinuses, palate and nasopharynx is innervated by post-sympathetic fibres from superior cervical ganglion through maxillary nerve. Stimulation of nasal mucosa causes severe cardiovascular response through this pathway. ${ }^{7}$ Oral clonidine and atenolol effectively attenuate tachycardia as well as hypertension without causing postoperative sedation.

Careful consideration of all factors regarding the control of bleeding throughout the entire perioperative period is required.

Preoperative preparations and intraoperative techniques and novel surgical material and technique will help to improve the quality of surgical field. ${ }^{1}$

\section{Preoperative Evaluation}

Coagulation comprises 3 major components: Vascular compartment, platelets and coagulation factors. Problem with any of the components can lead to bleeding. History of unexplained bleeding associated with surgical procedures, trauma, unexplained bruises or haematomas, family history suggesting bleeding tendency and use of prescribed and overthe-counter medications and supplements needs to be evaluated. Preoperatively, investigate the presence of petechiae, ecchymotic lesions, telangiectasias, hepatosplenomegaly and haemarthrosis of the joints. Preoperative coagulation profile will help to confirm a suspected diagnosis and for preoperative planning.

Discontinuation of warfarin for 5 days and aspirin and clopidogrel for 7 days is advisable. Surgery can be done if INR is less than 1.5. Patients who pose moderate-to-high risk for thromboembolic phenomena should receive LMWH 3 days before surgery. Preoperative embolisation is rarely needed only in cases of vascular tumours, which can be done 24 to 72 hours before surgery. Preoperative administration of steroid is beneficial due to their anti-inflammatory and antioedematical effects. This can improve visibility of field.

\section{Anaesthesia Considerations}

Controlled Hypotension: It includes various modalities associated with different potency and adverse effects. The safety is dependent on thorough knowledge about mechanism of action for each modality, adequate monitoring of the patient's haemodynamic instability especially in patients with a history of hypertension or ischaemic heart disease.

Induced hypotension exposes the patients to more anaesthetic drugs and hence higher risk of potential side effects. Neither of these methods guarantees a desirable surgical field with no bleeding. Therefore, investigators are working on more effective and safer methods to reduce bleeding and hence to improve the field of endoscopic sinus surgery. ${ }^{7}$

Preoperative steroids can be given in cases of severe nasal polyposis for its anti-inflammatory effect and decrease in mucosal oedema. An ideal hypotensive agent should be easy to administer with short time to onset, effects should disappear quickly when discontinued with rapid elimination of toxic metabolites with negligible effects on vital organs and with predictable and dose dependent effects. ${ }^{5}$
Proper precautions need to be taken during hypotensive anaesthesia like protection of pressure points by padding, monitoring of ECG especially V5 lead with ST segment analysis to detect cardiac ischaemia, maintaining normocapnia, avoidance of hypothermia as it decreases the effectiveness of vasodilators, maintaining adequate perfusion to all vital organs. ${ }^{6}$

Capillaries consist of just one layer of epithelial (lining) cells held in place by a 'Skeleton' of cross-linked collagen fibres embedded in a matrix of laminin which 'glues' the lining cells to the collagen net. The gel/laminin structure supporting basement membranes and is a component of all blood vessels.

Vitamin C works its bleeding by the synthesis and deposition of both collagen and laminin.

As vitamin $C$ is used up and excreted quickly, we have to administer 3 or 4 doses of $500 \mathrm{mg}$ of vitamin in a day. For collagen production, scientists have used vitamin $C,{ }^{6}$ other dietary antioxidants, minerals, proline and lysine.

Ethamsylate is thought to stabilise capillaries, reinforcing capillary membranes by polymerising hyaluronic acid. ${ }^{8}$

Ethamsylate limits capillary bleeding through its action on hyaluronic acid and initial studies showed a reduction in intraventricular haemorrhage.

Ethamsylate may also have an effect on the microcirculation, encouraging platelet aggregation and vasoconstriction and hence haemostasis. It also inhibits the effects of the prostaglandin-mediated vasodilatation and increased capillary permeability, hence reducing oedema through capillary leakage. 8,9

The other oral drugs which can be used for bloodless field are alpha agonists and B blockers, NTG, sodium nitroprusside and magnesium sulphate, opioids like remifentanil. Some disadvantages have been reported of these techniques including delayed recovery from inhaled anaesthetics, resistance to vasodilators and cyanide toxicity for nitroprusside.

\section{Role Oral and Intravenous of Beta Blocker}

Atenolol is a selective B1 blocker vasoconstriction of the mucous membrane arterioles and pre-capillary sphincters results from unopposed alpha-adrenergic effects of the endogenous catecholamines and the increased sympathetic tone. ${ }^{7}$

Oral bisoprolol has been used.10,11

Esmolol can be given as intravenously $500 \mathrm{mg} / \mathrm{kg} / \mathrm{min}$ as a bolus over 10 minutes after induction followed by infusion at the rate of $100-300 \mathrm{mg} / \mathrm{kg} / \mathrm{min}^{12}$

Esmolol is found to be superior as compared to other hypotensive agents.

\section{Role of Local, Oral and Intravenous Alpha-2 Agonists}

The role of oral clonidine is desirable to enhance the hypotensive action of inhalational agents without disadvantages of intravenous vasodilators. ${ }^{13}$

Clonidine is centrally acting selective partial alpha-2 adrenergic agonist. Clonidine stimulates alpha-2 adrenergic inhibitory neurons in medullary vasomotor centre resulting in decrease in sympathetic outflow from CNS to peripheral tissue resulting in decreased blood pressure, heart rate, cardiac output and results in peripheral vasodilation. 
Dexmedetomidine ${ }^{14,15,16}$ is being used in the loading dose $1 \mathrm{mg} / \mathrm{kg} 20$ minutes before induction of anaesthesia. The alpha- 2 receptors are involved in regulating the autonomic and cardiovascular systems. Alpha- 2 receptors are located on blood vessels where they mediate vasoconstriction on stimulation and in the brain act on sympathetic terminals where they inhibit norepinephrine release.

Use of dexmedetomidine in providing better surgical field and less blood loss during controlled hypotension was reported during tympanoplasty, septoplasty and maxillofacial surgeries. ${ }^{16}$

Advantage of dexmedetomidine is that it has inherent analgesic, sedative and anaesthetic sparing properties, which avoid administration of multiple drugs and their side effects.

The effect of total intravenous anaesthesia using propofol has been compared with inhalational anaesthesia using sevoflurane. ${ }^{17}$

\section{Role of Magnesium}

It can be given as $10 \%$ Solution, $40 \mathrm{gm} / \mathrm{kg}$ bolus over a period of 10 minutes before the induction of anaesthesia followed by $15-30 \mathrm{mg} / \mathrm{kg} / \mathrm{hr}$ as infusion to achieve MAP of $55-65$ mmHg. ${ }^{14}$

Magnesium limits the outflow of calcium from sarcoplasmic reticulum and produces a vasodilating effect by increasing the synthesis of prostacyclin and inhibiting angiotensin-converting enzyme activity. It also reduces the need for analgesic and sedative drugs, as it is an NMDA receptor antagonist. 18

\section{Role of Vasodilators}

Glyceryl trinitrate $2-10 \mathrm{mg} / \mathrm{kg} / \mathrm{hr}$. biotransformation pathway produces nitric oxide and contributes directly to its vasodilating effect with $\mathrm{H}_{2}$ of 0.1 sec. ${ }^{12,20}$

Activation of fibrinolysis during and after surgery is a well-known phenomenon. Many mechanisms associated with coagulation disorders such as surgical trauma, blood loss and consumption of coagulation factors and platelets; systemic infusion of anti-fibrinolytic drugs have been used to reduce bleeding in various forms of surgery such as major orthopaedic surgery, adeno-tonsillectomy and endoscopic sinus surgery. ${ }^{16}$

\section{Antifibrinolytics}

Intravenous tranexamic acid has been shown to be very useful in reducing blood loss in coronary artery bypass, spinal surgery, scoliosis, maxillofacial surgery, orthotopic liver transplant and total hip or knee arthroplasty. ${ }^{21,22}$

Tranexamic acid has been used in tonsillectomy surgery in dose of $15 \mathrm{mg} / \mathrm{kg}$. It has also been used for control of blood loss for FESS in children. ${ }^{19,20}$ Tranexamic acid also has been used topically for control of bleeding in FESS. ${ }^{23}$

Ethamsylate is haemostatic drug used for control of dysfunctional uterine bleeding 8,9 and periventricular haemorrhage in children. ${ }^{24}$ Oral route has been used to control bleeding in dacryocystorhinostomy surgery and for control of epistaxis. ${ }^{25}$

Assessment of surgical field for bleeding will be according to category scale adapted from Fromme et al. ${ }^{10}$ According to this scale, category scale values of 2 and 3 for the surgical field are considered as ideal.

\section{Grade}

- $\quad 0$ - No bleeding, cadaveric condition.

- I- Slight bleeding, no suctioning of blood required.

- II- Slight bleeding, occasional suctioning required, surgical field not threatened.

- III- Slight bleeding; frequent suctioning required. Bleeding threatened surgical field a few seconds after suction removed.

- IV- Moderate bleeding, frequent suctioning required. Bleeding threatened surgical field.

The target Mean Arterial Pressure (MAP) between 55 and $65 \mathrm{mmHg}$ can be decided after revising previous studies, in which metabolic and hormonal responses were investigated in patients who were subjected to induced hypotension in an attempt to provide bloodless surgical field without hazard of tissue ischaemia. ${ }^{24}$

Patient positioning: Reverse Trendelenburg is a common surgical position. Head elevation reduces mean arterial pressure in the elevated part by about $2 \mathrm{mmHg}$ for each 2.5 $\mathrm{cm}$ above the cardiac level. This position reduces venous return from lower extremities, thereby reducing total blood loss.

Use of endotracheal intubation with mechanical ventilation has added advantage over the use of supraglottic airway devices. Ventilation with normocapnia has been advocated to minimise bleeding and optimising the surgical field.

Recent studies have demonstrated that high frequency jet ventilation reduces bleeding, but is not practical. $^{1}$

\section{Medications for Controlled Hypotension}

Inhalation anaesthetics VIMA: It decreases arterial blood pressure through peripheral vasodilatation due to blockage of alpha-adrenoceptors.

Total intravenous anaesthesia TIVA: Propofol and opioids.

Propofol poses risk of propofol infusion syndrome characterised by metabolic acidosis and circulatory collapse. Opioids are often used as adjunct of TIVA or VIMA. Antihypertensive agents to maintain MAP at $65-70 \mathrm{mmHg}$ to avoid organ hypoperfusion.

\section{Surgical Considerations}

Topical vasoconstrictors: Aim is to decongest the nasal cavity. E.g. Cocaine, epinephrine, phenylepinephrine, oxymetazoline. These drugs are not free from side effects. Haemostatic biomaterial application can be done topically.

Topical anti-fibrinolytics: Mechanism of action is to bind with the lysine site of plasminogen, which prevents fibrinolysis and stabilises the blood clot thus decreasing further bleeding. ${ }^{23,25}$

Gelatin thrombin matrix: It stops bleeding on an average of 2 minutes. ${ }^{26}$ Some studies reported its adverse effect, $27,28,29$ but one study evaluated its efficiency without complications. ${ }^{30}$

Others: Microporous polysaccharide hemispheres, 31,32 oxidised methylcellulose, ${ }^{33}$ fibrin glue, ${ }^{34}$ microfibrillar collagen $^{35}$ and gelatin sponges ${ }^{36}$ can be used to control intraoperative bleeding. There is lack of scientific evidence comparing the efficacy of these agents. 


\section{Surgical Techniques}

Hot water irrigation with 40 - 42 degrees saline reduces diffuse oozing from sinonasal mucosa. Mechanism may include formation of oedema and narrowing of intranasal lumen which contributes to the compression of the leaking vessel, decreasing the flow, cleaning of blood coagulates from the nose.

Direct control of feeding vessels is another surgical technique. ${ }^{37,38}$ It can be done with endoscopic bipolar electrocautery or radiofrequency coagulator. ${ }^{39,40}$

\section{Injected and Topical Local Anaesthetics and Vasoconstrictors}

These can help to relieve postoperative pain, decrease blood loss, mucosal congestion. Commonly used vasoconstrictors are cocaine and phenylephrine.

Systemic absorption of these agents may cause hypertension tachycardia and other arrhythmias, hence should be continuously used in patients with CAD, CHF, malignant arrhythmias and those with MAOI.

The dose of phenylephrine should not exceed $0.5 \mathrm{mg}$ in adults ( 4 drops of $0.25 \%$ solution) or $20 \mathrm{mg} / \mathrm{kg}$ in children up to $25 \mathrm{~kg}$.

The topical application of epinephrine 1:100000 may effect same as injected epinephrine during FESS.

Body temperature: Maintenance of normothermia is vital for function of platelets and coagulation factors are essential for haemostasis.

Maintenance of anaesthesia depth: Manoeuvers like absence of PEEP will help preventing high intrathoracic pressure and will not impair venous drainage and hence will not increase surgical bleeding. ${ }^{1}$

Choice of anaesthetic agent: VIMA or TIVA can reduce arterial blood flow and glow through ethmoidal and supraorbital artery which supply ethmoid, sphenoid and ethmoid sinus. ${ }^{40}$

\section{CONCLUSION}

Various strategies have been tried to minimise intraoperative bleeding and improve the endoscopic surgical field. Various surgical techniques and anaesthetic techniques enhance the ability of each other to control bleeding. Cooperation between surgeon and anaesthesiologist and proper utilisation of one or two techniques will help provide better surgical field in endoscopic sinus surgery.

\section{REFERENCES}

[1] Thongrang C, Kasemsiri P, Chrrau RL, et al. Control of bleeding in endoscopic skull base surgery: current concepts to improve hemostasis. ISRN Surgery 2013;(2013):1-11. Article ID 191543.

[2] Baker AR, Baker AB. Anaesthesia for endoscopic sinus surgery. Acta Anaesthesiol Scand 2010;54(7):795-803.

[3] Gupta D, Srivastava S, Dubey RK, et al. Comparative evaluation of atenolol and clonidine premedication on cardiovascular response to nasal speculum insertion during trans-sphenoid surgery for resection of pituitary adenoma: A prospective, randomised, double-blind, controlled study. Indian Journal of Anaesthesia 2011;55(2):135-40.

[4] Lindop MJ. Complication and morbidity of controlled hypotension. British J Anaesth 1975;47(7):799-805.
[5] Khalifa OSM, Awad OG. A comparative study of dexmedetomidine, magnesium sulphate or glyceryl trinitrate in deliberate hypotension during functional endoscopic sinus surgery. Aims Sham Journal of Anesthesiology 2015;8(3):320-6.

[6] Larsen HR. Living with Warfamin. The AFIB Report www.afibbers.org.

[7] Patel NK, Pandya MR. A comparative study of tranexamic acid and ethamsylate in menorrhagia. Int Journal Basic \& Clinical Pharmacol 2012;1(2):85-90.

[8] Chamberlain G, Freeman R, Price F, et al. A comparative study of ethamsylate and mefenamic acid in dysfunctional uterine bleeding Br J Obstet Gynaecol 1991;98(7):707-11.

[9] Ethamsylate pharmacology and usage details/ Medicine India https:/www.medicineindia.org/Generic medicines > E

[10] Nair S, Collins M, Hung P, et al. The effect of betablocker premedication on the surgical field during endoscopic sinus surgery Laryngoscope 2004;114(6):1042-6.

[11] Jacob SM, Chandy TT, Cherian VT. Oral bisoprolol improves surgical field during functional endoscopic sinus surgery. J Anaesthesiol Clin Pharmacol 2014;30(1):59-64.

[12] Boezaart AP, van der Merwe J, Coetzee A. Comparison of sodium nitroprusside- and esmolol-induced controlled hypotension for functional endoscopic sinus surgery. Canadian Journal of anaesthesia 1995;42(5 Pt 1):373-6.

[13] Jabalameli M, Hashemi SM, Soltani HA, et al. Oral clonidine premedication decreases intraoperative bleeding in patients undergoing endoscopic sinus surgery. J of Research in Medical Sciences 2005;10(1):25-30.

[14] Bajwa SJ, Kaur J, Kulshrestha A, et al Nitroglycerine, esmolol and dexmedetomidine for induced hypotension during functional endoscopic sinus surgery: a comparative evaluation. J Anaesthesiol Clin Pharmacol 2016;32(2):192-7.

[15] Jamaliya RH, Chinnachamy R, Maliwad J, et al. The efficacy and hemodynamic response to Dexmedetomidine as a hypotensive agent in posterior fixation surgery following traumatic spine injury. J Anesthesiol Clin Pharmacol 2014;30(2):203-7.

[16] Kumari AR, Upendranatha I, Singh BD, et al. Dexmedetomidine versus propofol and fentanyl for controlled hypotensive anaesthesia in functional endoscopic sinus surgery. JEBMH 2015;2(36):578292.

[17] Alimain M, Mohseni M. The effect of intravenous tranexamic acid on blood loss and surgical field quality during endoscopic sinus surgery: a placebo-controlled clinical trial. J Clin Anaesth 2011;23(8):611-5.

[18] Bayram A, Ulgey A, Güneş I, et al. Comparison between magnesium sulfate and dexmedetomidine in controlled hypotension during functional endoscopic sinus surgery. Rev Bras Anestesiol 2015;65(1):61-7.

[19] Soliman R, Alshehri A. Assessment of the effect of tranexamic acid on perioperative bleeding in pediatric patients undergoing tonsillectomy. Egyptian Journal of Anaesthesia 2015;31(4):297-301. 
[20] Veien M, Sorensen JV, Madsen F. Tranexamic acid given intraoperatively reduces blood loss after total knee replacement: a randomized controlled study. Acta Anaesthesiol Scand 2002;46(10):1206-11.

[21] Neilipovitz DT, Murto K, Hall L, et al. A randomized trial of tranexamic acid to reduce blood Transfusion for scoliosis surgery. Anaesthesia Analgesia 2001;93:82-7.

[22] Jahanshahi J, Hashemian F, Pazira S, et al Effect of topical tranexamic acid on bleeding and quality of surgical field during functional endoscopic sinus surgery in patients with chronic rhinosinusitis: a triple blind randomized clinical trial. PLoS One 2014;9(8):e104477.

[23] Newton MC, Chadd GD, O’Donoghue B, et al. Metabolic and hormonal response to induced hypotension for middle ear surgery. British Journal of Anaesthesia 1996;76:352-7.

[24] Athanasiadis T, Beule AG, Wormald PJ. Effects of topical antifibrinolytics in endoscopic sinus surgery: a pilot randomized controlled trial. Am J Rhinol. 2007;21(6):737-42.

[25] Gall RM, Witterick IJ, Shargill NS. Control of bleeding in endoscopic sinus surgery: use of a novel gelatin-based hemostatic agent. J Otolaryngol 2002;31(5):271-4.

[26] Antisdel JL, Janney CG, Long JP, et al. Hemostatic agent microporous polysaccharide hemospheres (MPH) does not affect healing or intact sinus mucosa. Laryngoscope 2008;118(7):1265-9.

[27] Chandra RK, Conley DB, Kern RC. The effect of floseal on mucosal healing after endoscopic sinus surgery: a comparison with thrombi-soaked gelatin foam. Am J Rhinol 2003;17(1):51-5.

[28] Shrime MG, Tabaee A, Hsu AK. Synechia formation after endoscopic sinus surgery and middle turbinate medialization with and without floseal. Am J Rhinol 2007;21(2):174-9.

[29] Woodsworth BA, Chandra RK, LeBenger JD, et al. A gelatin-thrombin matrix for hemostasis after endoscopic sinus surgery. Am J Otolaryngol 2009;30(1):49-53.
[30] Sindwani R. Use of novel hemostatic powder MPH for endoscopic sinus surgery: initial impressions. Otolaryngol- Head and Neck Surg 2009;140(2):262-3.

[31] Antisdel JL, Matijasec JL, Ting JY, et al. Microporous polysaccharide hemosheres do not increase synechiae after sinus surgery: randomized controlled study. Am J Rhinol Allergy 2011;25(4):268-71.

[32] Phookan G, Davis AT, Holmes B. Hemangioendothelioma of the cavernous sinus: case report. Neurosurgery 1998;42(5):1153-6.

[33] Sekhar LN, Natarajan SK, Manning T, et al. The use of fibrin glue to stop venous bleeding in the epidural space, vertebral venous plexus, and anterior cavernous sinus: technical note. Neurosurgery 2007;61(3 Suppl):E51.

[34] Kim EH, Ahn JY, Chang JH, et al. Management strategies of intercavernous sinus bleeding during transsphenoidal surgery. Acta Neurochir (Wien) 2009;151(7):803-8.

[35] Fraser JF, Mass AY, Brown S, et al. Transnasal endoscopic resection of a cavernous sinus hemangioma: technical note and review of the literature. Skull Base 2008;18(5):309-15.

[36] Snyderman CH, Pant H, Carrau RL, et al. What are the limits of endoscopic sinus surgery?: the expanded endonasal approach to the skull base. Keio J Med 2009;58(3):152-60.

[37] Lee JT, Keschner DB, Kennedy DW. Endoscopic resection of juvenile nasopharyngeal angiofibroma. Operative Techniques in Otolaryngology 2010;21(1):56-65.

[38] Ruiz JW, Saint-Victor S, Tessema B, et al. Coblation assisted endoscopic juvenile nasopharyngeal angiofibroma resection. Int J Pediatr Otorhinolaryngol 2012;76(3):439-42.

[39] Ye L, Zhou X, Li J, et al. Coblation-assisted endonasal endoscopic resection of juvenile nasopharyngeal angiofibroma. J Laryngol Otol 2011;125(9):940-4.

[40] Ahn HJ, Chung SK, Dhong HJ, et al. Comparison of surgical conditions during propofol or sevoflurane anaesthesia for endoscopic sinus surgery. Br J Anaesth 2008;100(1):50-4. 